\title{
Malignant melanoma of the optic nerve head in a case of oculodermal melanocytosis
}

\author{
Mehmet Unal, Ilhan Gunalp, Alastair Deery, Ismet Durak, Selim Erekul, Orhan Bulay
}

$\begin{array}{ll}\text { Numune Hospital, } & \text { melanocytosis. After presentation the patient } \\ \text { Ankara } & \text { refused surgery for } 19 \text { months and the pro- } \\ \text { M Unal } & \text { gression of the tumour necessitated an } \\ \text { I Durak } & \text { exenteration of the orbit. }\end{array}$

Department of

Ophthalmology, Ankara Medical School, Ankara I Gunalp

\section{Department of} Pathology, Royal Free Hospital and School of Medicine, Hampstead,

A Deery

\section{Department of} Pathology, Ankara

Medical School, Ankara, Turkey

S Erekul

O Bulay

Correspondence to:

Associate Professor M Unal, Buklum Sokak 51/8,

Kavaklidere, 06660, Ankara, Turkey.

Accepted for publication 30 October 1991

Oculodermal melanocytosis (ODM) or naevus of Ota is a congenital benign melanocytic hyperpigmentation of deep periorbital skin and ocular tissue. The condition is most commonly unilateral and is more frequent in females. Malignant melanomas of the choroid, ${ }^{23}$ iris, ciliary body, ${ }^{5}$ orbit, ${ }^{67}$ brain, ${ }^{8}$ and skin ${ }^{9}$ have previously been reported in cases of ODM. We present for the first time a malignant melanoma apparently arising in the optic nerve head of a patient with ODM.

\section{Case report}

CLINICAL

A 60-year-old Caucasian man was known to have London, UK

\begin{abstract}
Malignant melanoma of the uveal tract, orbit, and brain have been reported to occur in patients with oculodermal melanocytosis. A 60-year-old Caucasian man with oculodermal melanocytosis developed a malignant melanoma of the optic nerve head in the left eye. This case is the first reported example of a malignant melanoma developing in the optic nerve associated with oculodermal melanocytosis. After presentation the patient gression of the tumour necessitated an
\end{abstract}

Figure 1 Photograph demonstrating oculodermal melanocytosis in the left eye.

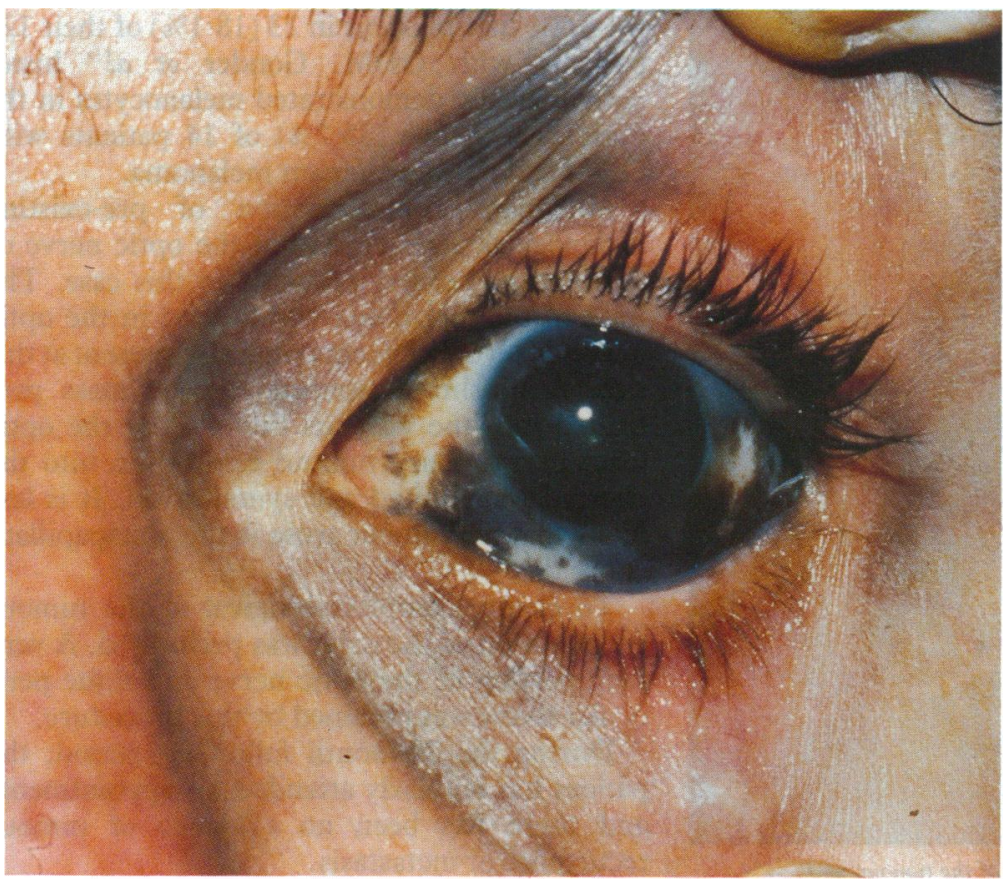

dark pigmentation of his eye and eyelids since childhood. When he presented to the Tumour Clinic of the Department of Ophthalmology of Ankara Medical School in May 1987 his only complaint was a crescent-shaped dark area in front of his left eye. Visual acuity was $6 / 9$ in this eye. His right eye and eyelids were normal and visual acuity was $6 / 6$. He had ODM involving his left eye and eyelids (Fig 1). In this eye ocular motility and intraocular pressure were normal and there was no proptosis. A relative afferent pupillary defect was detected on the affected side.

On the slit-lamp there were irregular patches of pigmentation in all quadrants of the episclera and the iris was thick and pigmented. Ophthalmoscopic examination revealed a pigmented mass involving the optic disc and extending superonasally in the choroid. Its dimensions were clinically estimated to be $5 \times 3 \times 1 \mathrm{~mm}$ (Fig $2)$. Fluorescein angiography supported the presence of a malignant melanoma (Fig 3).

An orbital computed tomographic (CT) scan demonstrated a well circumscribed tumour of $8 \mathrm{~mm}$ in diameter located in the anterior aspect of the optic nerve. The tumour appeared confined to the optic nerve sheath. It extended into the vitreous cavity through the optic nerve head (Fig 4). CT of the head, liver scintigraphy, chest roentgenogram, liver enzyme studies, complete blood count, and urinalysis including melanin and vanillyl mandelic acid were found to be normal.

The patient was informed about the grave situation and enucleation was offered to him but he refused it. He was seen 2 months later in July 1987 and described a rapid loss of vision since his first visit. Visual acuity in his left eye was found to have deteriorated to light perception.

In October 1987, 5 months after presentation, he lost light perception. Ophthalmoscopically the mass had grown in size and extended further into the vitreous. Retinal and preretinal haemorrhages were present on and around the optic nerve head. Some lens opacities were also noted in the left eye. He still refused surgery and did not attend for further appointments.

In January 198919 months after presentation the patient returned with a painful glaucomatous and cataractous left eye. Intraocular pressure by applanation was $60 \mathrm{~mm} \mathrm{Hg}$ and the cornea was oedematous. Further extension of the tumour was suspected and an exenteration of the orbit was performed. Both eyelids were preserved.

PATHOLOGY

Macroscopically the material consisted of the eye and periocular tissues. The eye measured $24 \times$ 


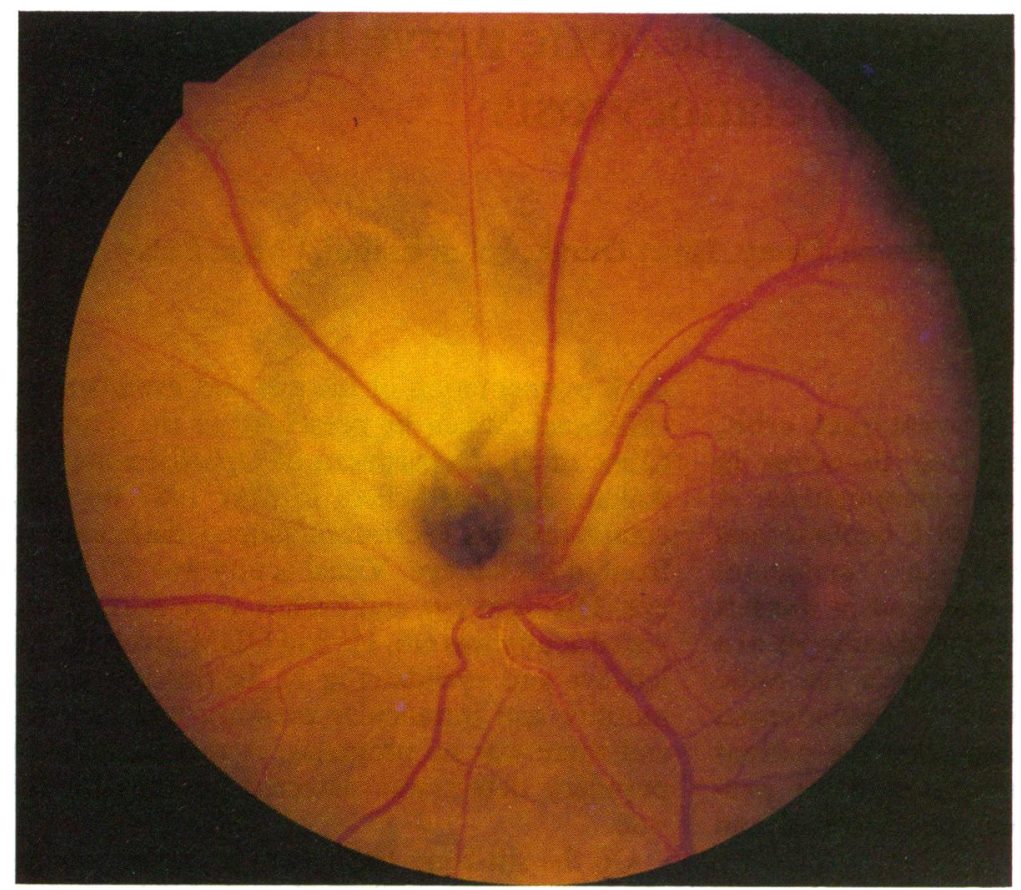

Figure 2 Fundus photograph of the left eye showing pigmented tumour located on the optic disc.

$24 \times 24 \mathrm{~mm}$ with an $18 \mathrm{~mm}$ optic nerve which became detached. The optic nerve was thickened and firm on palpation. It measured $10 \mathrm{~mm}$ in diameter anteriorly immediately behind the globe. At this point the tumour infiltrated and replaced the optic nerve and the nerve had become detached from the globe, during manipulation through the plane of soft tumour tissue.

The globe was then sectioned through the

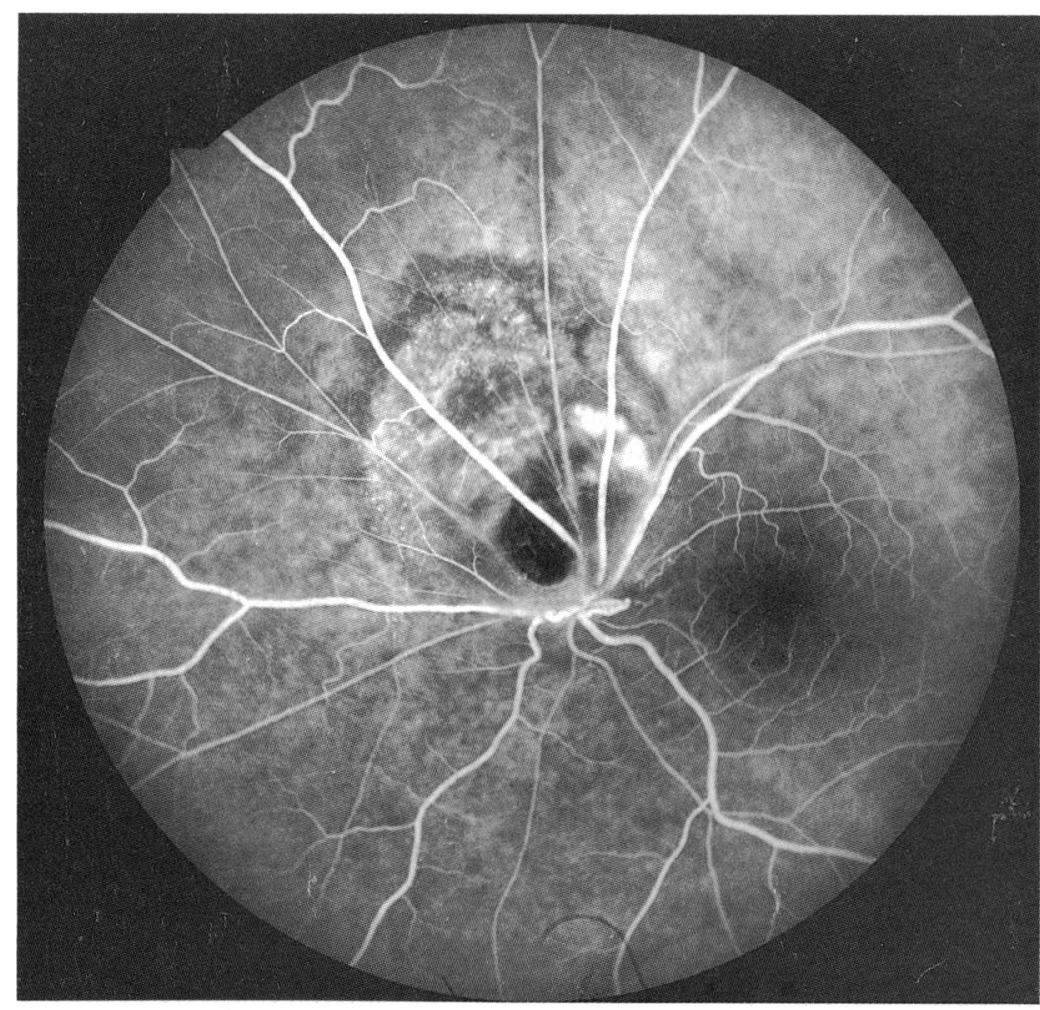

Figure 3 Fluorescein angiogram demonstrates hyperfluorescence of the tumour. meridional plane revealing a mushroom-shaped pigmented tumour mass with diameters $9 \times 7 \times 6$ $\mathrm{mm}$ extending from the optic disc forwards into the vitreous cavity. The tumour base extended into the choroid $4 \mathrm{~mm}$ circumferentially. Pigmented tumour intruded into the meninges of the optic nerve to a point $13 \mathrm{~mm}$ from its point of origin on the posterior aspect of the globe (Fig 5 ). The optic nerve was macroscopically normal at the site of surgical transection.

Upon microscopy the tumour was composed of heavily pigmented epithelioid and plump spindle melanocytes with large numbers of interspersed coarsely pigmented melanophages. The melanoma infiltrated deeply into the nerve head and the subarachnoid space (Fig 6) ensheathing the nerve for much of its length and penetrating the dural sheath forming an extradural mass.

Foci of small bland polyhedral epithelioid and thin spindle naevus cells were present at one anterolateral margin of the intravitreous tumour and within the most anterior part of the optic nerve behind the lamina cribosa suggesting, perhaps, pre-existent naevus. No such foci were present within the tumour extensions into the choroid. Within the anterior chamber there was evidence of melanomalytic glaucoma.

\section{Discussion}

Aberrant pigmentation of ODM consists of fusiform or dendritic melanocytes lying in deeper layers of facial skin and globe. The melanocytes normally migrate from the neural crest during embryogenesis and settle superficially in skin and mucous membranes. ODM represents a developmental anomaly in which some melanocytes fail to reach these surface structures. ${ }^{1610}$

These melanocytes which migrate via the distribution of nerves have been demonstrated along ciliary nerves, ${ }^{7}$ intrascleral channels, ${ }^{6}$ and in orbital tissues. ${ }^{11}$ They have also been found in optic nerve leptomeninges" and in lamina cribrosa of the optic nerve ${ }^{12}$ in eyes with ODM.

Teekhasaenee et $a l^{\prime}$ reported pigmentation of the optic disc to occur in $23(18 \cdot 1 \%)$ of their 127 patients with ODM. Gonder et $a l^{13}$ histopathologically demonstrated melanocytes in the optic disc in five $(35 \cdot 7 \%)$ of 14 patients with ODM and uveal malignant melanoma.

Malignant transformation of pre-existing melanocytes arrested within the optic nerve or optic nerve head is probable in this case. The bulk of the melanoma was located in the optic nerve. Naevoid elements were also present at this site. A mushroom-shaped tumour mass protruded into the vitreous cavity from the optic disc; peripapillary tumour infiltration into the choroid was limited and symmetrical. It is less likely that the tumour arose in the juxtapapillary choroid.

To ensure complete removal of the tumour exenteration of the orbit was performed. A very long portion of the optic nerve and some periocular tissue was obtained by this procedure.

During the 28-month follow-up period, the patient has regularly attended his appointments and there has been no evidence of tumour recurrence or metastasis. 


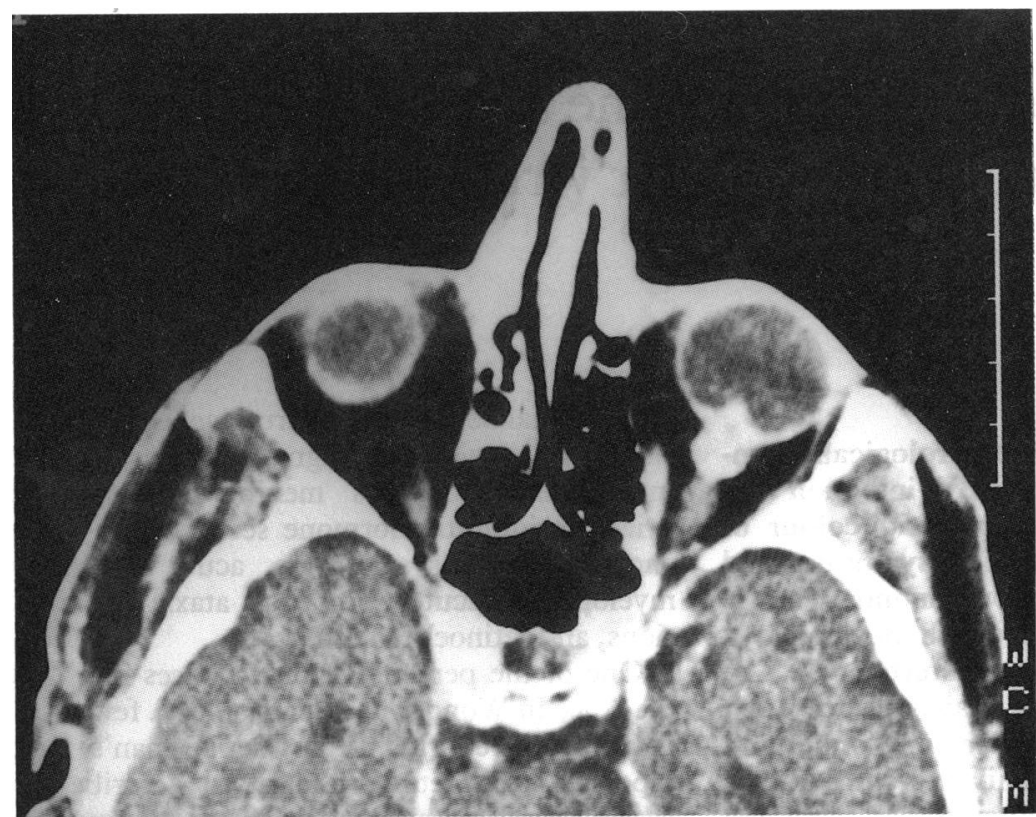

Figure 4 Orbital computed tomographic scan of the orbits showing a tumour located in the anterior portion of the left optic nerve.

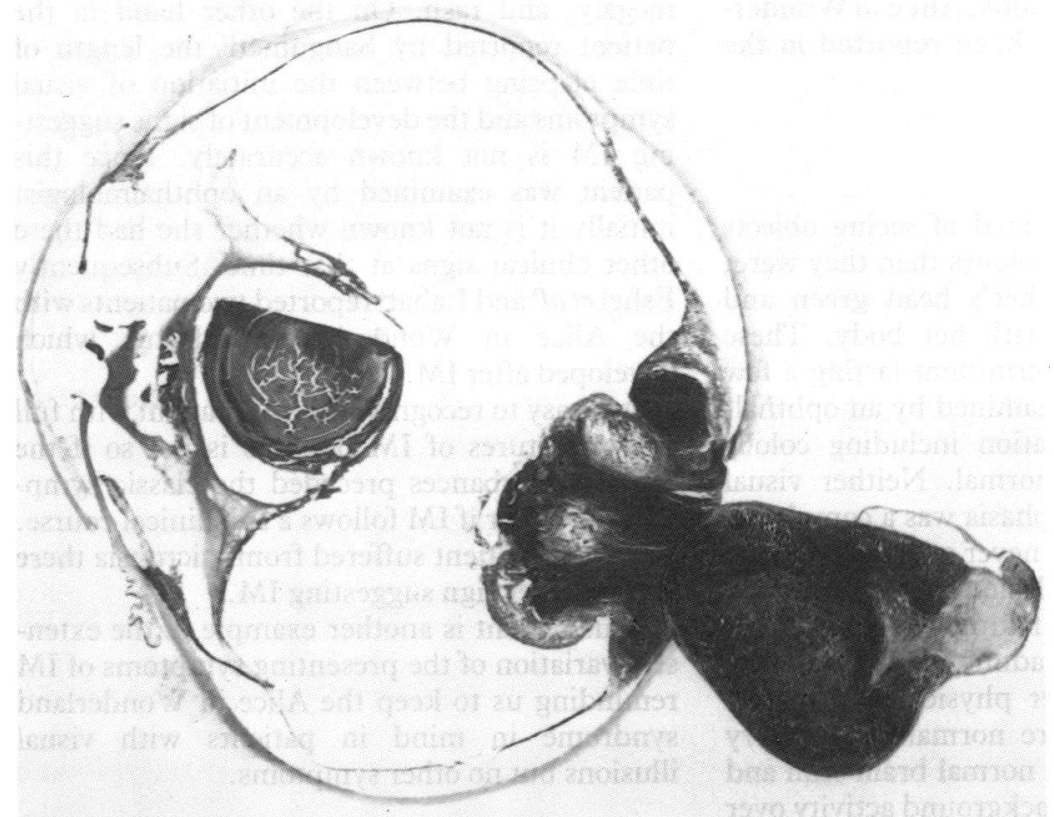

Figure 5 Two separate sections through globe and optic nerve repositioned to reveal tumour in nerve head and subarachnoid sheath. The most posterior portion of the nerve which was clear of tumour is not included ( $H \mathcal{E} E$ E stain).

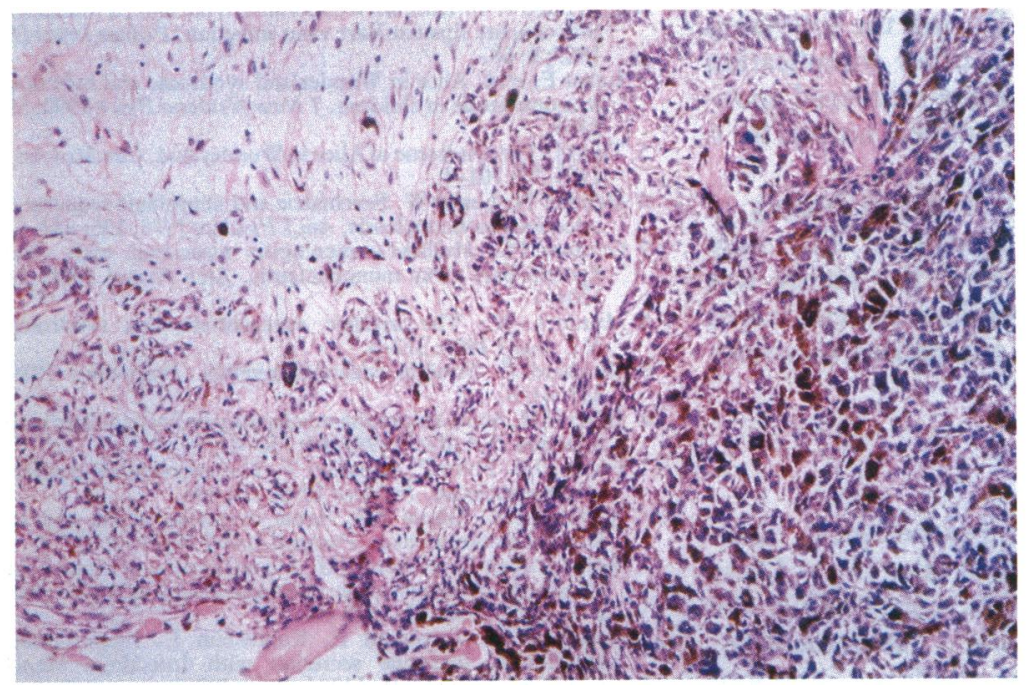

Figure 6 Melanoma involving meningeal sheath and infiltrating optic nerve ( $H \mathcal{E} E$ stain. Magnification $\times 70$ ).
1 Teekhasaenee C, Ritch R, Rutnin U, Leelawong N. Ocular findings in oculodermal melanocytosis. Arch Ophthalmol 1990; 108: 1114-20.

2 Gonder JR, Shields JA, Shakin JL, Albert DM. Bilateral ocular melanocytosis with malignant melanoma of the choroid. Brf Ophthalmol 1981; 65: 843-5.

3 Nik NA, Glew WB, Zimmerman LE. Malignant melanoma the choroid in the naevus of Ota of a black patient. Arch Ophthalmol 1982; 100: 1641-3.

4 Font RL, Reynolds AM Jr, Zimmerman LE. Diffuse malignant melanoma of the

in the naevus of Ota. Arch Halasa A Malignant melanoma

Ota. Arch Ophthalmol 1970; 84: 176-8.

6 Jay Arh Ophthalmol 1970, 84: 176-8. 年 359-63.

7 Rice CD, Brown HH. Primary orbital melanoma associated with orbital melanocytosis. Arch Ophthalmol 1990; 108: $1130-4$.

8 Sang DL, Albert DM, Sober AJ, McMeekin TO. Nevus of Ota with contra-lateral cerebral melanoma. Arch Ophthalmol 1977; 95: 1820-4.

9 Dorsey CS, Montgomery H. Blue nevus and its distinction from Mongolian spot and the nevus of Ota. F Invest Dermatol from Mongolian spo

10 Dutton JJ, Anderson RL, Schelper RL, Purcell JJ, Tse DT. Orbital malignant melanoma and oculodermal melanocytosis: report of two cases and review of the literature. cytosis: report of two cases and

11 Shields JA. Primary melanocytic tumors. In: Diagnosis and management of orbital tumors. Philadelphia: WB Saunders, $1989 ; 17: 280$.

12 Reese AB. Pigmented tumors. In: Tumors of the eye. 3rd edition. Hagerstown: Harper and Row; 1976; 7: 187.

13 Gonder JR, Shields JA, Albert DM, Augsburger JJ, Lavin PT. Uveal malignant melanoma associated with ocular and oculodermal melanocytosis. Ophthalmology 1982; 89: 95360. 